\title{
o Cotidiano na Investigação em Saúde Pública: um recorte teórico e metodológico
}

\section{The Everyday Life in Public Health Research: a theoretical and methodological framework}

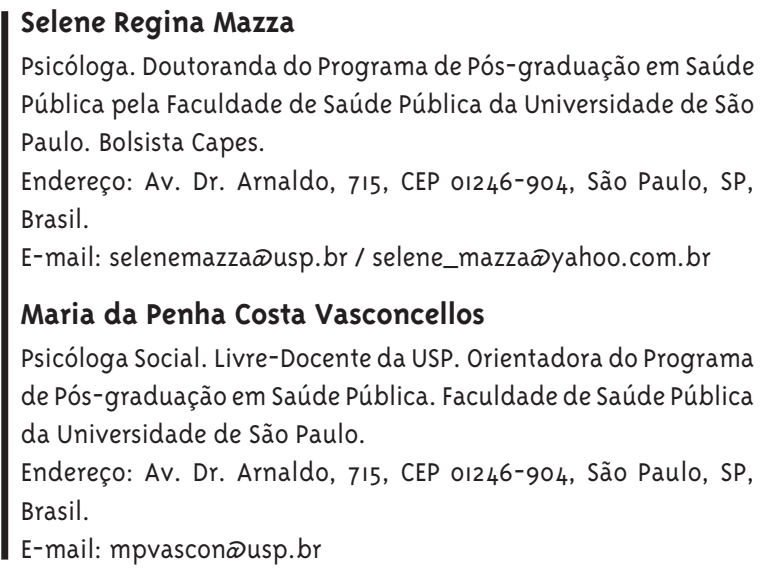

E-mail: mpvascon®usp.br

\section{Resumo}

O objetivo deste artigo é apresentar algumas reflexões acerca das possibilidades investigativas do cotidiano através da análise dos modos de vida, que ampliem perspectivas ao campo de pesquisa em saúde pública, considerando que o estudo dos modos de vida no cotidiano envolve a análise das trajetórias que contextualizam rotinas, interações e significados de vida. Isso possibilita ao pesquisador social do campo da saúde, a partir de um enquadre teórico, uma flexibilização metodológica que oferece mobilidade na escolha da técnica que melhor favoreça o entendimento da questão a ser investigada. Tem-se aqui, como referência conceitual, a ideia de um cotidiano investigado a partir de processos e contextos interativos, em oposição a uma objetivação categorial entre sujeito e objeto. Nesse contexto, partindo da reflexão teórica, toma-se como referencial empírico da pesquisa, a sala de espera do ambulatório do Serviço de Metabolismo Osteoarticular de um Posto de Saúde na cidade de Fortaleza/CE, no intuito de tornar possível uma compreensão interpretativa do cotidiano que envolve as situações de vida e de saúde de mulheres com osteoporose.

Palavras-chave: Modos de vida; Metodologia; Saúde pública; Sociologia do cotidiano. 


\section{Abstract}

The aim of this paper is to present some reflections on possibilities to investigate everyday life by examining ways of life, so as to broaden perspectives to the field of research in public health, in light of the fact that the study of daily ways of life involves the analysis of trajectories that contextualize routines, interactions and meanings of life. This allows the social researcher in the health field to have, based on a theoretical framework, a flexible methodology that offers mobility in the choice of the technique that best favors the understanding of the issue to be investigated. We have here, as a conceptual reference, the idea of everyday life investigated from interactive processes and contexts, as opposed to a categorial objectification between subject and object. In this context, from the theoretical reflection, we take, as the research's empirical reference, the waiting room of the outpatient clinic of the Osteoarticular Metabolism Department of a Health Care Unit in the city of Fortaleza/, Northeastern Brazil, in order to foster an interpretive understanding of the daily routine that involves the life and health situations of women with osteoporosis.

Keywords: Ways of Life; Methodology; Public Health; Sociology of Everyday Life.
Quando o intuito é pesquisar os modos de vida das pessoas, o cotidiano torna-se um campo rico e fértil, pois “[...] é um lugar privilegiado da análise sociológica na medida em que é revelador, por excelência, de determinados processos do funcionamento e da transformação da sociedade e dos conflitos que a atravessam" (Pais, 2003, p. 72), tornando-se de significativa relevância para pesquisas sociais em saúde pública.

O objetivo deste artigo é apresentar algumas reflexões acerca das possibilidades investigativas do cotidiano através da análise dos modos de vida, que ampliem perspectivas ao campo de pesquisa na saúde pública, considerando que o estudo dos modos de vida no cotidiano envolve a análise das trajetórias que contextualizam rotinas, interações e significados de vida.

Os modos de vida, com múltiplas formas de expressão, delineiam aspectos comuns e incomuns de histórias e vivências. Essa multiplicidade expressiva, percebida na vida cotidiana, possibilita ao pesquisador do campo da saúde, a partir de um enquadre teórico, uma flexibilização metodológica que oferece mobilidade na escolha da técnica que melhor favoreça o entendimento da questão a ser investigada.

Para tanto, tem-se aqui, como referência conceitual, a ideia de um cotidiano investigado a partir de processos e contextos interativos, em oposição a uma objetivação categorial entre sujeito e objeto, pois se "conceitos, categorias e estruturas se mostram como elementos operacionais nas pesquisas sobre a vida cotidiana, isto é, facilitam nossas análises e evocam um certo ar de academia, penso que acabamos pagando um preço alto por isso, à medida que nossas análises ficam confinadas aos limites que essas alternativas metodológicas nos impõem" (Ferraço, 2007, p. 77).

Nesse âmbito, partindo da reflexão teórica, tomase como referencial empírico a sala de espera do ambulatório do Serviço de Metabolismo Osteoarticular de um Posto de Saúde na cidade de Fortaleza-CE ${ }^{1}$.

1 Este artigo faz parte da pesquisa de doutoramento no Programa de Pós-graduação em Saúde Pública da Universidade de São Paulo, com apoio (bolsa de doutorado) da Coordenação de Aperfeiçoamento de Pessoal de Nível Superior (Capes), desenvolvida com mulheres diagnosticadas com osteoporose, e teve como um dos campos de investigação a sala de espera. Essa pesquisa foi aprovada pelo Comitê de Ética em Pesquisa da Faculdade de Saúde Pública, conforme a Resolução No 196/96. 
O intuito deste trabalho é enfatizar a importância de uma compreensão interpretativa do cotidiano que envolve as situações de vida e de saúde de mulheres com osteoporose. Ressalta-se que o cotidiano, é entendido a partir de uma perspectiva sociológica, possibilitando olhares além das causas e conseqüência das doenças, tornando-se uma campo fértil para uma análise compreensiva, indo além de condicionamentos e mediações relativas ao processo saúde-doença.

Ressalta-se que a vida cotidiana está em permanente interação, o que possibilita encontrar diversidade de informações no conjunto de fenômenos e experiências na qual se define uma realidade manifesta.

\section{Conceituando o Cotidiano}

Por ser uma noção teórica, o cotidiano pode apresentar diversas vertentes explicativas e compreensivas que delineiam formas distintas de se pesquisar. Nesse caso, a problematização da questão investigativa suscita a referência de determinados autores pelo critério teórico que cada um representa. Assim, a pesquisa do cotidiano pauta-se em linhas teóricas oriundas de disciplinas distintas, mas que possibilitam maior amplitude no campo analítico.

Acredita-se que sistematizar o conceito sobre cotidiano é por demais complexo. Diante do enfoque a que este artigo se propõe, faz-se necessário apresentar algumas noções conceituais que poderão iluminar melhor o campo compreensivo na pesquisa dos modos de vida.

No Brasil, merece destaque o trabalho de Mary Jane Spink, que apresenta uma produção teórica profícua sobre o tema, além de ser referência a um número significativo de pesquisas da área psicológica e da saúde. Sua perspectiva metodológica "baseiase no estudo do saber cotidiano, focalizando as maneiras pelas quais as pessoas produzem sentidos e posicionam-se nas relações sociais, no lócus onde se produzem e significam determinadas práticas e com a preocupação de desnaturalizar as construções do cotidiano" (Guareschi, 2004, p.10).

Tendo como enfoque a abordagem construcionista e concepções de âmbito interdisciplinar, o cotidiano é entendido como reflexo das práticas sociais que transpõem a vida das pessoas, não é a realidade em si e sim o movimento de acontecimentos que se efetivam no dia a dia. Trata-se da observação dos sentidos que são construídos no contexto das relações sociais através das práticas discursivas, na interligação dos aspectos de atuação, produção e uso da linguagem.

0 atravessar do cotidiano envolve uma perspectiva temporal, inscrevendo historicamente os repertórios construídos na dialogia, estabelecendo sentidos antigos e novos. Essa temporalidade é definida por Spink e Medrado (1999) como a interface entre o tempo longo que envolve conteúdos culturais de certa época, o vivido, que ressignifica os conteúdos históricos apreendidos pelos processos sociais e experiências pessoais, e, por fim, o tempo curto que é indicado pelos processos dialógicos e que torna possível o entendimento da dinâmica da produção de sentidos.

Ao dar sentido ao mundo, o indivíduo estabelece parâmetros, circunscreve o seu agir, desenvolve atividades e constrói ideias em suas práticas sociais, produzindo rupturas e ressignificações em suas posturas identitárias. Isso compõe o cotidiano em microlugares como produto e produtor dos processos sociais (Spink, 2008).

Assim entendido, o campo de pesquisa acontece no cotidiano, em que há um reposicionamento do pesquisador fazendo parte "do próprio cotidiano, não como um pesquisador participante e muito menos como um observador distante, mas simplesmente como parte." (Spink, 2008, p. 72). Trata-se de propiciar a criação de espaços que possibilitem a reflexão ético-política na produção de conhecimentos compartilhados, focalizando a pesquisa-intervenção e os diversos textos e imagens que circulam no cotidiano, compreendendo os repertórios utilizados para dar sentido às ações de vida (Spink e Guareschi, 2008).

A noção de campo de pesquisa estende-se além das estruturações metodológicas clássicas, a situação é o tema e o espaço simultaneamente para a investigação. Não se perde a referência ética necessária, porém amplifica-se a análise de distintos fluxos de ação e compreensão.

Podem-se encontrar outros posicionamentos sobre o cotidiano, pautados no arcabouço teórico 
da sociologia, distintos do apresentado anteriormente e que fundamentam diversas estratégias investigativas. Conforme Pais (2003): o formismo desenvolvido por Simmel, Balandier e Maffesoli; o interacionismo, em especial, o de Goffman; e o marxismo por Henri Lefebvre e Agnes Heller. Além da grande contribuição trazida por Schutz (1962) através do interacionismo simbólico.

A leitura sociológica, nesta perspectiva, apóia-se na interpretação da vida cotidiana, não a associando a um mero processo repetitivo de costumes, que utiliza o senso comum de forma banalizada, "o senso comum não é apenas instrumento das repetições e dos processos que imobilizam a vida de cada um e de todos." (Martins, 2008, p. 52).

Assim, a reflexão deste estudo parte do princípio que a vida cotidiana é percebida como um espaço revelador da realidade social e que se orienta, em sua análise, a partir da sociologia do cotidiano, visível nas ideias propostas por José Machado Pais.

A partir desse prisma, Pais (2003) salienta a dificuldade de isolar a vida cotidiana da realidade social que a compõe, pois para se conceber analiticamente o cotidiano é necessário extrapolar o senso comum, indo além da repetição categorial das atividades de vida diárias, ou seja, a "vida quotidiana pede sempre um complemento circunstancial. Vida quotidiana de quem?, em que situação?, em que contexto?" (Pais, 2003, p. 115).

Isso remete ao desenvolvimento de percursos de entendimento, alicerçados em uma perspectiva histórica, de espaços e tempos de existência, o que implica mostrar a constituição do cotidiano através de contextos que se estruturam na ação e no desenvolvimento de acontecimentos circunscritos a partir de posições, relações e vinculações de acordo com a situação que ocupam em certa realidade.

Pais (2003) apresenta ainda a noção de contextos dos indivíduos e contextos analíticos. 0 primeiro está correlacionado ao compartilhamento cotidiano de idealizações normativas, mas não determinado pela ação individual, ou seja, os indivíduos interpretam seus contextos no intuito de condicionar o rumo de suas ações a partir de aspectos relevantes ao seu exercício de interação, tendo como referência normas e condutas das práticas cotidianas. 0 segundo considera o contexto social como instrumento analítico de utilização e observação do espaço da realidade, da percepção de acontecimentos e da estrutura explicativa rígida. Ele toma os referentes simbólicos para a leitura e a construção do social através do retalhamento da realidade marcado nos discursos, trajetórias e histórias que dão contornos aos modos de vida.

A vida cotidiana, vista como objeto de conhecimento científico, é tema da consciência social contemporânea, pois oferece concepções peculiares e próprias do modo de viver e de ser dos indivíduos, indo além de aspectos rotineiros da vida individual e social, de usos e costumes, tendo qualidade própria e historicidade (Martins, 2008).

Portanto, deve ser considerado que o cotidiano se produz e reproduz nas relações sociais de forma processual, por meio de mediações simbólicas e materiais, que ocorrem no campo da experiência e constroem significados peculiares, conseqüentemente incorporando distintas implicações, podendo ser analisadas nos modos de se levar a vida.

\section{Os Modos de Vida Cotidianos: a sala de espera como campo de pesquisa}

Quando o campo de pesquisa envolve questões referentes ao cotidiano de indivíduos e grupos, depara-se, inicialmente, com dois caminhos a serem seguidos: a análise numérica ou a contextual (discursiva) da realidade Alguns optam por uma terceira via, que abrange os dois tipos de análise. Independentemente do caminho que seja tomado, todos apresentarão conclusões distintas e válidas para a questão a que se quer responder.

Se o propósito é a compreensão da realidade visualizada em sua essência, a análise contextual pode ser o caminho mais indicado, pois a análise da vida vivida, quando observada em suas construções e interações, expõe redes de práticas sociais que incluem as diversidades individuais e coletivas, pois o "novo herói da vida é o homem comum imerso no cotidiano. É que no pequeno mundo de todos os dias está também o tempo e o lugar da eficácia das vontades individuais, daquilo que faz a força da sociedade civil, dos movimentos sociais" (Martins, 2008, p. 52). 
No sentido de articular essa diversidade expressa cotidianamente, neste estudo optou-se por percorrer espaços que possibilitassem colecionar fatos, processos e contextos, assim como servir como lócus de observação inicial de trajetórias e acontecimentos que marcam histórias pessoais.

Para isso, adotou-se a sala de espera ${ }^{2}$ do ambulatório do Serviço de Metabolismo Osteoarticular de um Posto de Saúde em Fortaleza-CE como um campo e espaço profícuo de observação. É nesse cenário que, a cada semana, ocorrem trinta e cinco consultas, em média, para diagnóstico e tratamento da osteoporose em mulheres situadas no período da vida entre 50 a 85 anos.

Na sala de espera, aguardando a consulta médica, as mulheres exploram novas socialidades através de narrativas sedimentadas em trajetórias construídas sobre as imagens e histórias de suas vidas. Nas palavras de Simmel (2006, p. 75), "formas de interação da conversa, que de resto estão a serviço de inúmeros assuntos e finalidades das relações humanas, tem aqui seu significado em si mesmas, quer dizer, no estímulo do jogo da relação que elas estabelecem entre indivíduos que se unem ou se separam, que vencem ou subjugam-se, recebem ou dão. 0 sentido duplo de 'entreter-se' ", validando a importância da conversa como um traço da sociabilidade e da convivência social.

Ao pesquisador também cabe esperar - para escutar, observar e anotar -, pois é na contextualização das experiências dessas mulheres que ocorre a ancoragem de significados construídos rotineiramente. Elas acontecem no âmbito social, ou seja, nos diálogos e nas negociações que se estabelecem na espera de uma consulta médica e que tem a sala como lócus de identificação e de pertencimento grupal.

É nessa sala, onde estão à espera de algo, que se definem realidades em um processo contínuo de interação. Nesses termos, "o estabelecimento de um mundo comum não se limita a constituir o quadro do sentido ou a definir as razões da experiência vivida; além de conferir sentido ao desenrolar das acções e dos discursos que os indivíduos trocam entre si, define igualmente a identidade dos papéis que representam" (Rodrigues, 1993, p. 122).

Assim, a diversidade de experiências compõe um quadro de representações identitárias, efetivadas através dos modos de vida no cotidiano, visíveis em uma dimensão dramatúrgica e interativa (Goffman, 2007), a uma apresentação diante dos outros incorporando valores comuns e reconhecidos socialmente e que, mediante a isso, certos aspectos da vida cotidiana são regulados, limitados e mitificados.

Exemplo disso é percebido no conteúdo das conversas que não envolvem o motivo da consulta (osteoporose). Observam-se relatos sobre a condição de vida atual, tais como: problemas com marido, filhos e dinheiro ou outros eventos sociais significativos, que aparecem como fenômenos comuns a todas elas, constituindo-se em um processo identificatório mútuo, citados por elas como "mazelas da vida”. A sala de espera, além de funcionar como um local de socialidades, oferece conteúdos relevantes, com suas especificidades ao pesquisador social no campo da saúde.

Nesse contexto, são formuladas representações reveladas e ocultas da realidade, com a intenção de focalizar "cenários" familiarizados, visto que o cotidiano é construído através de inferências que ocorrem no processo interacional entre os indivíduos que ora se posicionam como atores ora como personagens, a partir dos artifícios que são ajustados às diversas situações de vida (Goffman, 2007) e espelhadas através dos modos de viver.

Quando elas, mulheres que supõem terem osteoporose, chegam para a primeira consulta, a expectativa quanto ao diagnóstico é visível, pois em um processo interativo, procuram "analisar" o resultado da ultra-sonografia associando as cores presentes no laudo médico com um possível diagnóstico positivo ou negativo, ou seja, quando na tabela colorida o "X" está na cor verde significa que a pessoa não tem osteoporose, na cor amarela que ela está "quase" com osteoporose e na cor vermelha que "a coisa tá feia”. Compartilham informações que cada uma traz de sua vivência subjetiva, mas que encontra ressonância coletiva.

Apoiando-se nos argumentos de Langdon (1995),

2 Essa temática também é abordada na dissertação de mestrado de LOPES, S. M. B. Cultura, linguagem e fonoaudiologia: uma escuta do discurso familiar no contexto da saúde pública. São Paulo, 2001. Faculdade de Saúde Pública - USP. 
que concebe saúde e doença como processos psicobiológicos e socioculturais, resultantes de contextos culturais e experiências subjetivas de sofrimento ${ }^{3}$, pode-se compreender que elementos simples (supostamente), como o resultado de uma ultra-sonografia, possibilitam um parâmetro de análise entre a ação e o discurso. Entre suposições sobre cores (verde, amarelo ou vermelho), elas discutem quem tem "saúde" e "doença".

É nesse momento que a sala de espera revela como são construídos processos psicobiológicos relacionados à osteoporose. A cor torna-se o artifício para simbolizar e revelar outros aspectos associados à experiência subjetiva do sofrimento diante da possibilidade de ter ou não osteoporose como a dor sentida no corpo, a alimentação que pode estar (na perspectiva dela) incorreta ${ }^{4}$, a falta de exercícios, a família desestruturada, entre outros.

Revela-se que o adoecer, entre essas mulheres, está entrelaçado com a vida diária, através das queixas sobre o difícil acesso ao sistema de saúde e, sobretudo, como espaço de sociabilidade para expressarem as condições financeiras insuficientes, as descobertas de novos pontos de crochê, novas receitas culinárias. Mais do que um tempo de espera, a sala de espera torna-se um espaço de experiências. Para Langdon (1995), o sistema de saúde é um sistema cultural, com significados fundamentados em específicas disposições institucionais e modelos interativos interpessoais, que integram elementos relacionados à saúde e dão ao indivíduo sinais que possibilitam a interpretação e a ação diante de sua doença.

O tempo de existência (a vida dessa mulher) passa a ser definido pelos significados que se estruturam rotineiramente, pautam-se nas mudanças que poderão ocorrer na vida a partir da osteoporose. É nessa circunstância que saúde e doença tomam relevâncias distintas na vida de cada mulher. A osteoporose passa a ser compreendida como um processo social mediante o qual as ações se fundamentarão no significado que lhe será dado.

A osteoporose, mesmo sendo mais amplamente discutida dentro de um modelo biomédico clínico, traduz em narrativas de uma sala de espera que trajetórias de vida são elementos constituintes importantes, mediante o reconhecimento da doença e o posicionamento a respeito do tratamento. Isso significa, apoiado nos argumentos de Langdon (1995), que a osteoporose, como doença, precisa ser compreendida como um processo subjetivo fundado em contextos socioculturais e experienciado pelos atores.

Assim, seguindo essa ideia, a osteoporose, através de representações simbólicas, expressa não somente o mundo, mas revela na experiência vivida como são incorporados os processos psicofisiológicos de saúde e doença a ponto de influenciarem os processos corporais (Langdon, 1995).

Os processos corporais condicionam a maneira de ver a vida e de falar sobre ela. Portanto, a sala de espera, como espaço de pesquisa, possibilita conhecer a ambiência de vida dos sujeitos de uma investigação, tornando-se via de acesso para a observação da multiplicidade de acontecimentos e ações do dia a dia, estruturando recortes informativos heterogêneos, que fundamentam os diversos contextos cotidianos. Isso suscita a compreensão de que as atividades vivenciadas rotineiramente incorporam atos reflexivos, oriundos de ordenamentos culturais impositivos (do passado) e da capacidade interventiva da realidade, dando origem a novas representações, ou seja, a reflexividade transformadora, que possibilita considerar o cotidiano como um espaço aberto a experiências (Pais, 2007).

\section{Indagações sobre a Vida Cotidiana e suas Implicações para o Campo de Pesquisa na Saúde}

Na sociologia do cotidiano, os estudos enfocam percepções, crenças e valores culturais de pessoas e/ou grupos, buscando o significado de ações e práticas sociais. Pautam-se em relatos de experiência, uso de imagens, registros detalhados/densos e a observação in loco como recurso metodológico de investigação.

\footnotetext{
3 Segundo Langdon (1995), na perspectiva da antropologia, a cultura é entendida de forma dinâmica e heterogênea e a doença é compreendida como processo e experiência.

4 Muitas mulheres com osteoporose associam a falta de cálcio a uma dieta pobre de derivados do leite. (Mazza e col., 2004)
} 
Em outros estudos, distintos da sociologia do cotidiano, o que prevalece são análises relacionadas diretamente ao processo saúde-doença, em que as inferências fundamentam-se essencialmente no fenômeno em si, não transcendendo o nível objetivo que a realidade apresenta, exemplificando o restrito conhecimento sobre a vida cotidiana e suas implicações no campo da saúde e talvez atrelado ao escasso exercício investigativo das dinâmicas, que norteiam a vida rotineira dos indivíduos, pelo "fato de que para certos setores do conhecimento há uma primazia dos critérios ortodoxos de cientificidade e, ao mesmo tempo, certa resistência a posturas teórico-metodológicas que privilegiam as relações humanas como objeto da investigação científica" (Leite e Vasconcellos, 2007, p. 170).

As contribuições dessa forma de pesquisar são inegavelmente indispensáveis, contudo a pluralidade de significados que permeiam a vida cotidiana permitem apresentar outras "facetas", que compõem o processo saúde-doença, ou seja, "estender o olhar sobre o sujeito e sobre o campo de interações entre indivíduos, grupos e instituições e a cultura subjacente" (Leite e Vasconcellos, 2006, p. 115).

Essa questão é percebida quando o campo acontece em um espaço real e concreto, ou seja, neste estudo, a sala de espera, que proporcionou elementos de análise entre a ação e o discurso de mulheres que se apresentam como sujeitos além da doença (osteoporose).

Quando esses elementos tornam-se alvo do estudo dos modos de vida cotidianos em saúde, exige-se uma relação peculiar entre pesquisador e informante, em que as relações também compõem o campo de análise e apresentam informações específicas sobre a temática investigada. Assim entendido, o processo de pesquisa acontece no cotidiano. 0 componente humano na pesquisa reflete a apreensão de categorias subjetivas que ordenam a vida e as práticas sociais e não somente representações preestabelecidas conceitualmente, ou seja, a doença por si só. Afinal, interessa o que está além, com quem e em qual contexto a doença se situa.

Entende-se, então, que a pesquisa sobre a vida cotidiana envolve o lidar com a imprevisibilidade na ação investigativa, exigindo o aporte de aspectos operacionais e éticos, que permitam apreender elementos da experiência do que é vivido, mesclando conhecimentos interdisciplinares que possibilitem captar imagens dos processos, construindo historicamente o viver cotidiano na saúde e na doença, pois "no espaço e no tempo da pesquisa no/do cotidiano, nos quais a interrogação dos sentidos que damos à pesquisa é permanente, não há refúgio teórico nem prático que separe os olhos dos que veem daquilo ou daqueles que são vistos" (Victorio Filho, 2007, p. 101).

Assim, a abordagem do campo investigativo através dos modos de vida cotidianos torna-se mais apropriada quando o intuito é ter como objeto de estudo formas de cuidados da saúde. Leite e Vasconcellos (2006) argumentam que a complexidade da vida cotidiana, acrescida das representações que as doenças suscitam, em geral apresenta uma variância substancial entre os aspectos que sustentam o raciocínio dos profissionais de saúde e os diversos grupos que compõem uma sociedade, constituindo compreensões distintas, distanciadas e preconceituosas a partir de ambos.

Como se percebe, as experiências de ambos expressam contextos que configuram magnitudes e importâncias fundadas em compreensões distintas sobre determinado fato ou processo vivido. A vida cotidiana traduz historicidade e escolhas feitas dia a dia, refletindo-se no agir, falar, pensar e sentir.

Por isso, Victorio Filho (2007, p. 101) assinala que "a flexibilidade das ações investigativas deve ser permanente, para que se possa dialogar com a sucessão de acontecimentos que vibram o cotidiano e cujas relações não se mostram imediatamente claras, visto que os canais de ligação entre este ou aquele fato são rizomáticos, muitas vezes subterrâneos, muitas vezes invisíveis ao olhar interrompido na superfície das práticas”.

A dialogia com os acontecimentos cotidianos da vida possibilita ao investigador do campo da saúde distinguir analiticamente as dominâncias de modos de viver, que se revelam através da situação em si, com seus movimentos, saberes e práticas, pois, assim, a vida cotidiana torna-se um "tecido de maneiras de ser e de estar, em vez de um conjunto de meros efeitos secundários de "causas estruturais" (Pais, 2003, p. 30).

Anecessidade crescente de resultados que dimensionem qualitativamente as questões de saúde exige 
interpretações do ponto de vista da experiência de vida do indivíduo, de sua sociabilidade e da memória coletiva sobre os saberes da cura, da doença e das práticas terapêuticas, que fornecem informações provenientes de sentidos e significados dados aos elementos que compõem o contexto estudado. Principalmente, se envolve cuidados à saúde no processo de adoecimento, visto que as especificidades no cotidiano envolvem posicionamentos produzidos em situações de interação e apresentam pluralidades relevantes ao estudo do processo saúde-doença, não em partes, mas em um processo contínuo de construções e reconstruções.

A sociologia do cotidiano, compreendida na perspectiva apresentada neste artigo, contribui para a pesquisa em saúde, desde que se observe que a análise da vida cotidiana exige que se vá além dos fatos, buscando revelar o que cerca esses fatos (Pais, 2003), ou seja, o que os modos de vida tentam refletir verdadeiramente.

\section{Referências}

FERRAÇO, C. E. Pesquisa com o cotidiano. Revista Educação \& Sociedade, Campinas, v. 28, n. 98, p. 73-95, 2007.

GOFFMAN, E. A representação do eu na vida cotidiana. 14. ed. Petrópolis: Vozes, 2007.

GUARESCHI, N. M. Prefácio. In: SPINK, M. J. Linguagem e produção de sentidos no cotidiano. Porto Alegre: EDIPUCRS, 2004. p. 9-10.

LANGDON, J. E. A doença como experiência: a construção da doença e seu desafio para a prática médica. Disponível em: <http://www.cfh.ufsc. br/ nessi/A\%2oDoenca\%2ocomo\%2oExperiencia. htm>. Acesso em: 8 jun. 2011.

LEITE, S. N.; VASCONCELLOS, M. P. C. Negociando fronteiras entre culturas, doenças e tratamentos no cotidiano familiar. História, Ciências, Saúde: Manguinhos, Rio de Janeiro, v. 13, n. 1, p. 113-128, 2006.

LEITE, S. N.; VASCONCELLOS, M. P. C.

Construindo o campo da pesquisa: reflexões sobre a sociabilidade estabelecida entre pesquisador e seus informantes. Saúde e Sociedade, São Paulo, v. 16, n. 3, p. 169-177, 2007.
MARTINS, J. S. A sociabilidade do homem simples: cotidiano e história na modernidade anômala. São Paulo: Contexto, 2008.

MAZZA, S. R.; MOTA NETO, H.; LEITE, J.

A. D. Osteoporose: o olhar da paciente.

In: III CONGRESSO INTERNACIONAL DE OSTEOPOROSE E DOENCQAS OSTEOMETABÓLICAS, 2004, São Paulo. Sessão pôster.

PAIS, J. M. Vida cotidiana: enigmas e revelações. São Paulo: Cortez, 2003.

PAIS, J. M. Cotidiano e reflexividade. Revista Educação \& Sociedade, Campinas, v. 28, n. 98, p. 23-46, 2007.

RODRIGUES, A. D. Para uma sociologia fenomenológica da experiência quotidiana.

Revista Crítica de Ciências Sociais, Coimbra, n. 37, p.117-129, jun. 1993.

SCHUTZ, J. The problem of social reality. The Hague: Martinus Nijhoff, 1962. (Collected papers, 1).

SIMMEL, G. Questões fundamentais da sociologia. Rio de Janeiro: Zahar, 2006.

SPINK, P. K. O pesquisador conversador no cotidiano. Psicologia \& Sociedade, Porto Alegre, v. 20, p. 70-77, 2008. Edição especial.

SPINK, M. J. P.; GUARESCHI, N. M. Editorial da edição especial. Psicologia \& Sociedade, Porto Alegre, v. 20, p. 3-5, 2008. Edição especial.

SPINK, M. J. P.; MEDRADO, B. Produção de sentidos no cotidiano: uma abordagem teórico-metodológica para análise das práticas discursivas. In: SPINK, M. J. P. (Org.). Práticas discursivas e produção de sentidos no cotidiano: aproximações teóricas e metodológicas. São Paulo: Cortez, 1999. p. 41-61.

VICTORIO FILHO, A. Pesquisar o cotidiano é criar metodologias. Revista Educação \& Sociedade, Campinas, v. 28, n. 98, p. 97-110, 2007.

Recebido em: 01/10/2010

Reformulado em: 04/07/2011

Aprovado em: 22/08/2011 